\title{
De Noordzeeziekte, een unieke progressieve myoclonus epilepsie
}

De zogenaamde Noordzeeziekte is een zeer zeldzame progressieve myoclonus epilepsie, met een uniek fenotype en, vergeleken met de meeste andere progressieve myoclonus epilepsieën, een zeer vroeg debuut rond het tweede levensjaar met een langzaam progressief verloop. In deze bijdrage wordt stilgestaan bij de genetische en pathofysiologische rol van de causale mutatie in het GOSR2 gen en worden enkele aspecten van de behandeling besproken.

De Noordzeeziekte of ook wel North Sea progressive myoclonus epilepsy, is een zeldzame neurologische aandoening die wordt gekarakteriseerd door een combinatie van early-onset ataxie, myoclonus en epilepsie, waarvan de klachten met het ouder worden toenemen en die moeilijk te behandelen is. Alle patiënten hebben een mutatie in het GOSR2 gen, dit betreft in de meerderheid van de patiënten een homozygote variant (c.430G >T, p.Glyi44Trp). Opvallenderwijs zijn de geboorteplaatsen van alle voorouders terug te leiden naar landen grenzend aan de Noordzee: vermoedelijk is er bij het ontstaan van de aandoening sprake geweest van een stichter(founder)effect (Corbett et al., 20II). Het onderliggende ziektemechanisme is momenteel onduidelijk, al lijken de gliacellen belangrijke spelers te zijn in de pathofysiologie (Lambrechts et al., 2019). De Noordzee-ziekte is een zeer zeldzame aandoening, wereldwijd zijn er tot nu toe 28 patiënten beschreven (Polet et al., 2020).

\section{Overeenkomsten met Unverricht-Lundborg}

Fenotypisch heeft de Noordzeeziekte veel overeenkomsten met de ziekte van Unverricht-Lundborg, een andere vorm van Progressieve Myoclonus Epilepsie (PME). Kenmerkend voor PME is het progressieve verloop van myoclonus en epilepsie (Berkovic et al., I99I). Bij sommige vormen van PME (bijvoorbeeld de ziekte van Lafora) is sprake van cognitieve achteruitgang: dit staat bij de Noordzeeziekte echter niet op de voorgrond. Daarnaast is ataxie bij de Noordzeeziekte meer prominent aanwezig dan bij de meeste vormen van PME. De combinatie van ataxie en myoclonus met weinig tot geen cognitief verval wordt ook beschreven bij actiemyoclonus nierfalen syndroom en Myoclonus Epilepsie en Ataxie ten gevolge van Kalium kanaal mutaties (MEAK), die onder het Progressieve Myoclonus Ataxie (PMA) spectrum vallen (van der Veen, 2018). De Noordzeeziekte heeft met weinig tot geen cognitief verval, prominente ataxie en progressieve myoclonus en epilepsie kenmerken van zowel PME en PMA, en neemt daarmee een bijzondere positie in op het grensvlak tussen beide entiteiten.

\section{Fenotype}

Uit een relatief groot cohortonderzoek van zeventien Noordzeeziekte patiënten ( 5 tot 46 jaar) blijkt aan de hand van retrospectieve data en gestructureerde interviews een kenmerkend scala aan symptomen en uitlokkende factoren die de klachten verergeren (Polet et al., 2020). Deze auteurs beschreven een zeer homogeen en karakteristiek verloop van de Noordzeeziekte, gekenmerkt door een vroeg debuut van ataxie, gevolgd door het ontstaan van corticale myoclonus en epilepsie (figuur I). De klachten beginnen al heel vroeg. Tussen het eerste en vierde levensjaar ontstaan de eerste symptomen gepaard gaande met coördinatiestoornissen, wat zich vooral uit in een vertraagde motorische ontwikkeling, onhandigheid en vaak vallen. Bij lichamelijk onderzoek is er daarnaast ook sprake van areflexie en frequent hypotonie. Differentiaal diagnostisch wordt daarbij soms aan een spierziekte gedacht, ook omdat bij veel patiënten het Creatine Kinase (CK) verhoogd is (Polet et al., 2020). Rond het vijfde levensjaar ontstaan spierschokken (myoclonus): deze zijn initieel distaal het meest prominent, met name in de handen en rond de mond. Naarmate patiënten ouder worden verspreidt dit zich en spreekt men van gegeneraliseerde myoclonus. De myoclonieën zijn aanwezig in rust, nemen toe bij actie en zijn stimulus-sensitief (aanraking, geluid, lichtflitsen) (van Egmond et al., 2014). De myoclonus is een corticale myoclonus en staat aanvankelijk los van epileptische fenomenen, maar uiteindelijk ontwikkelen patiënten epilepsie, doorgaans al vóór de leeftijd van tien jaar. De aanvallen zijn gegeneraliseerd met een motorisch begin (tonisch-clonisch en myocloon) alsmede gegeneraliseerd met een niet-motorisch begin (absences). Een aantal patiënten rapporteren een toename in myoclonieën in de dagen vóór een epileptische aanval, gevolgd door een afname in myoclonieën na de epileptische aanval. Dit laat zien dat er een belangrijke samenhang is tussen het hyperkinetische fenotype met myoclonieën en de epilepsie. Echter, het grootste verschil is dat de myoclonieën constant 
doorsluimeren, terwijl de epileptische aanvallen acuut optreden in episodes. De ernst van de epilepsie in de Noordzeeziekte varieert: een deel van de Noordzeeziekte patiënten heeft dagelijks moeilijk te behandelen epileptische aanvallen, daarentegen zijn er ook patiënten met slechts sporadisch epileptische aanvallen (Polet et al., 2020). Naast ataxie, myoclonus en epilepsie wordt bij een aantal patiënten syndactylie, pes cavus en/of scoliose gevonden, wat kan helpen in het stellen van de juiste diagnose.

Stress, koorts, maar ook 'externe' warmte zoals douchen of een warme omgevingstemperatuur lijken de klachten te verergeren (Lambrechts et al., 20I9). Infecties leiden vaak ook tot verslechtering van het algemeen functioneren: bij een aantal patiënten is beschreven dat zij na een infectie een terugval in motorische ontwikkeling doormakten (Polet et al., 2020). Het verloop van de Noordzeeziekte is progressief: over de jaren heen worden de schokken grover, kunnen de epileptische aanvallen zich ontwikkelen tot een status epilepticus en ontstaat er dysarthrie en soms ook dysfagie. Verder krijgen sommige patiënten te maken met drop attacks, vermoedelijk ten gevolge van negatieve myoclonieën in de onderste extremiteiten. De combinatie van evenwichtsproblemen, toenemende myoclonieën en drop attacks zorgt er voor dat patiënten vaak rond de puberleeftijd een rolstoel moeten gebruiken (Polet et al., 2020).

\section{Neurofysiologisch en beeldvormend onderzoek} In het EEG van patiënten met de Noordzeeziekte komt focale (vooral occipitaal) en multifocale gegeneraliseerde epileptiforme activiteit voor in de vorm van pieken, golven, piekgolfcomplexen en poly-piekgolfcomplexen. Vaak is er sprake van een traag achtergrondpatroon en een fotopa- roxysmale respons (Polet et al., 2020). De bevindingen bij het zenuwgeleidingsonderzoek en EMG zijn meer uiteenlopend; variërend van: geen opvallende afwijkingen, behoudens een afwezige H-reflex; bevindingen passend bij sensibele neuronopathie; bevindingen wijzend op motorisch voorhoornlijden; of een combinatie van deze afwijkingen. De afwezige H-reflex en het voorhoornlijden kunnen samenhangen met de afwezige reflexen en suggereren betrokkenheid van het perifere zenuwstelsel bij de Noordzeeziekte (Polet et al., 2020). Polymyografie toont een burstduur van minder dan Ioo ms en karakteristieken van zowel positieve als negatieve myoclonus: deze bevindingen bevestigen de corticale myoclonus (Polet et al., 2020). Beeldvorming met behulp van MRI toont in essentie geen afwijkingen, behoudens geringe cerebellaire atrofie bij een aantal patiënten (Polet et al., 2020). Er is éénmaal een autopsie beschreven, met als bevinding enige atrofie van het cerebrum en gliose van de basale kernen, zonder structurele afwijkingen passend bij neurodegeneratie (Corbett et al., 20II).

\section{Pathofysiologie}

De oorzaak van de Noordzeeziekte is gelegen in mutaties in het GOSR2-gen. Vrijwel alle tot op heden bekende patiënten hebben bovendien dezelfde homozygote mutatie, die in het eiwit leidt tot een enkele aminozuursubstitutie (glycine naar tryptofaan op positie I44, Gi44W) (Corbett et al, 20II; Polet et al., 2020). Er is één patiënt beschreven met het klinisch beeld van de Noordzeeziekte die naast heterozygotie voor deze mutatie, op het andere allel een deletie van drie baseparen had die leidt tot deletie van één aminozuur (Ki64del) (Praschberger et al., 20I5).

Hoe de genetische veranderingen in het GOSR2-gen precies leiden tot de Noordzeeziekte is vooralsnog onbekend. De aminozuurveranderingen Gi44W en KI84del, die bij alle

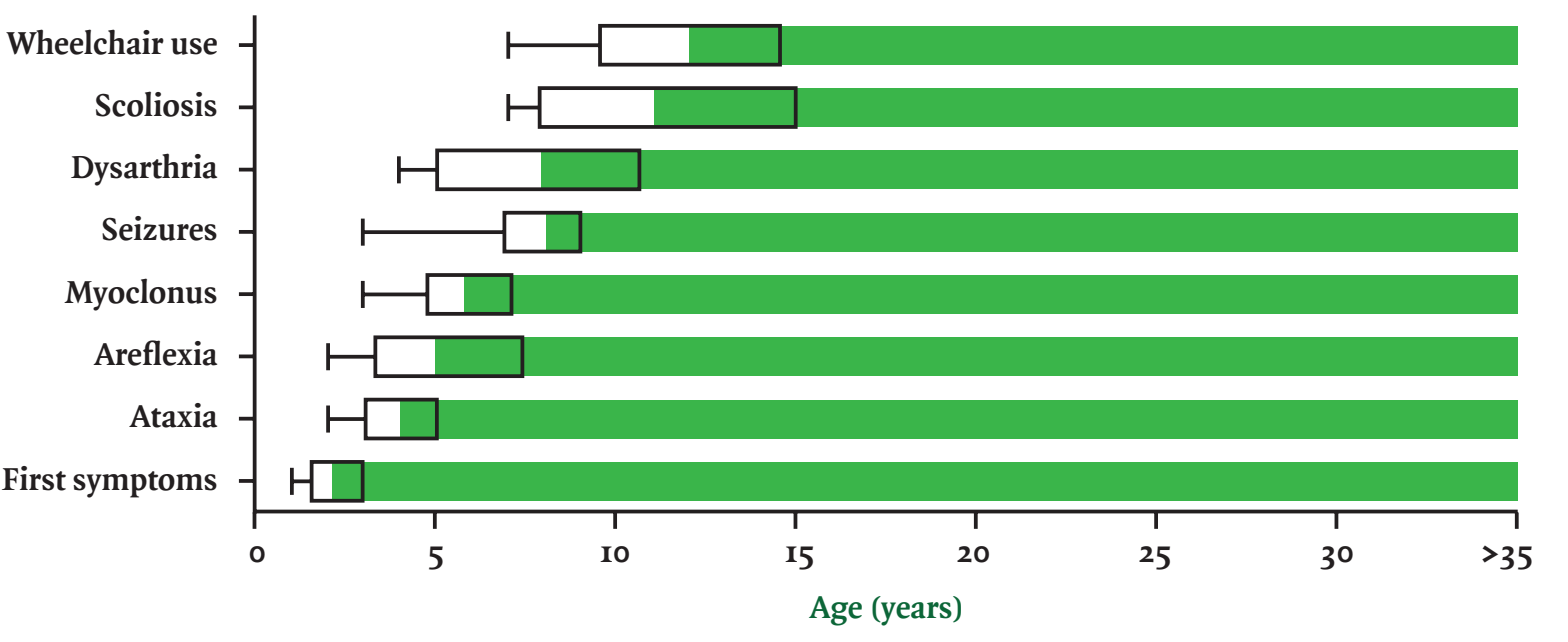

Figuur I Het verloop van de Noordzeeziekte: weergegeven is op welke leeftijd in jaren het betreffende symptoom voor het eerst werd gerapporteerd bij veertien van de zeventien patiënten die werden onderzocht (Uit: Polet et al., 2020) 
tot op heden gerapporteerde patiënten met de Noordzeeziekte gevonden worden, bevinden zich in het functionele SNARE-domein van het eiwit en leiden tot een partial loss of function van het eiwit (Corbett et al., 20II; Weiss et al., 20I9): wat aannemelijk maakt dat de SNARE-functie van GOSR2 beïnvloed wordt (Praschberger et al., 20I7).

\section{Onderzoek}

Op het niveau van de cel of van het organisme is onderzoek naar het ziektemechanisme minder vergevorderd. Om dit deel van de pathofysiologie beter te begrijpen, is door meerdere onderzoeksgroepen gebruik gemaakt van de fruitvlieg (Drosophila melanogaster) als modelorganisme (Praschberger et al., 2017). De fruitvlieg bevat een aan GOSR2 ortholoog eiwit genaamd membrin: het volledig uitschakelen (knockout) van membrin in de fruitvlieg leidt tot vroege lethaliteit in het larvale stadium, maar dit wordt deels hersteld door overexpressie van het humane GOSR2 gen. Dit toont aan dat GOSR2 in de mens en membrin in de vlieg elkaars functionele tegenhangers zijn. Als in de fruitvlieg het eigen membrin vervangen wordt door GOSR2 met mutaties die bij patiënten voorkomen, ontstaan afwijkingen in neuronen, waaronder veranderingen in dendritische morfologie en in het axonaal transport van bepaalde eiwitten (Praschberger et al., 2017).

Fruitvliegen met een knockdown van membrin in alle lichaamscellen (maar niet volledig uitgeschakeld) neigen tot ontwikkelen van epileptiform gedrag in respons op hitte, vergelijkbaar met wat bij patiënten optreedt (Lambrechts et al., 20I9). Knockdown van membrin beperkt tot alleen neuronen leidt verbazingwekkend genoeg in het geheel niet tot epileptiform gedrag; in plaats daarvan leidt knockdown in uitsluitend gliacellen wel tot epileptiforme verschijnselen, waarbij de gevoeligheid hiervoor toeneemt naarmate de vliegen ouder worden (Lambrechts et al., 20I9). Dit laatste weerspiegelt de progressieve aard van de Noordzeeziekte bij patiënten.

Deze laatste bevindingen ondersteunen een model waarin GOSR 2 zijn functie primair in glia uitoefent, en waarbij dysfunctie hiervan indirect effect heeft op het functioneren van neuronen. Er is slechts beperkte literatuur over gliale bijdragen aan epileptogenese: hierbij betreft het dan vaak verlies van controle over het neuronale micromilieu door onvoldoende klaring van ionen of neurotransmitters. Soortgelijke mechanismen zijn ook aangetoond in de fruitvlieg (Striano \& Belcastro, 2017). Dit rechtvaardigt het onderzoek naar het celbiologisch mechanisme achter de Noordzeeziekte met de fruitvlieg als model, waarbij gebruik gemaakt kan worden van een welontwikkelde toolbox van technieken op het gebied van genetica en moleculaire imaging. Daarnaast biedt het model de mogelijkheid om groepen medicijnen te screenen op effectiviteit.

\section{Behandeling}

De bovengenoemde kennis van de onderliggende pathofysiologie is nog niet vergevorderd genoeg om een gerichte behandeling of precision treatment te kunnen voorstellen. Vooralsnog is de behandeling van de Noordzeeziekte symptomatisch, waarbij een combinatie van verschillende anti-epileptica gebruikt wordt met als doel om myoclonus en epileptische aanvallen te onderdrukken. Gemiddeld krijgen patiënten drie tot vijf verschillende anti-epileptica, veelgebruikte medicijnen zijn clonazepam, levetiracetam en valproïnezuur waarvan bekend is dat ze effectief zijn tegen myoclonieën (Polet et al., 2020). Voorzichtigheid is geboden bij de keuze van anti-epileptica, omdat een aantal anti-epileptica zoals fenytoïne en carbamazepine bekend staan om het verergeren van myoclonus (Striano \& Belcastro, 20I7). Ondanks een combinatie van meerdere anti-epileptica blijven de myoclonieën vaak zeer uitgesproken aanwezig en is het lastig om de epileptische aanvallen geheel onder controle te krijgen. Het ketogeen dieet kan aan de behandeling worden toegevoegd, wat bij enkele patiënten uitkomst heeft geboden (van Egmond et al., 2017) Ook is in Zuid-Afrika bij drie patiënten diepe hersenstimulatie (DBS) van de caudale zona incerta toegepast, wat bij alle drie patiënten leidde tot minder gegeneraliseerde motor aanvallen, en in één patiënt een gunstig effect had op staan en lopen (Anderson et al., 20r6).

Vanzelfsprekend vormt de progressieve aard van de aandoening een voortdurende uitdaging voor elk van deze behandelingen.

\section{Conclusie}

De Noordzeeziekte wordt gekenmerkt door een progressief en invaliderend verloop, met het ontstaan van ataxie en myoclonus rond de peuterleeftijd, gevolgd door epilepsie vóór het tiende levensjaar, met areflexie en scoliose als bijkomende kenmerken. Hoewel precision medicine voor deze groep patiënten helaas nog niet binnen handbereik is, biedt de stand van het nog jonge onderzoek hoop voor de toekomst.

\section{Referenties}

Anderson DG, Németh AH, Fawcett KA, et al., Krause A. (2016) Deep Brain Stimulation in Three Related Cases of North Sea Progressive Myoclonic Epilepsy from South Africa. Mov Disord Clin Pract. I;4(2):249-53. Berkovic SF, So NK, Andermann F. Progressive myoclonus epilepsies: clinical and neurophysiological diagnosis. (I99I) J Clin Neurophysiol Off Publ Am Electroencephalogr Soc. 8(3):26I-74.

Corbett MA, Schwake M, Bahlo M, et al. (20II) A mutation in the Golgi Qb-SNARE gene GOSR2 causes progressive myoclonus epilepsy with early ataxia. Am J Hum Genet. I3;88(5):657-63. 
Lambrechts RA, Polet SS, Hernandez-Pichardo A, et al. (2019) North Sea Progressive Myoclonus Epilepsy is Exacerbated by Heat, A Phenotype Primarily Associated with Affected Glia. Neuroscience. 15;423:I-II.

Polet, SS, Anderson DG, Koens LH, et al. (2020) A detailed description of the phenotypic spectrum of North Sea Progressive Myoclonus Epilepsy in a large cohort of seventeen patients. Parkinsonism \& Related Disorders. 72 (2020), 44-48 PMID: 32105965.

Praschberger R, Balint B, Mencacci NE, et al. (2015) Expanding the Phenotype and Genetic Defects Associated with the GOSR2 Gene. Mov Disord Clin Pract. 2(3):27I-3.

Praschberger R, Lowe SA, Malintan NT, et al. (2017) Mutations in Membrin/GOSR2 Reveal Stringent Secretory Pathway Demands of Dendritic Growth and Synaptic Integrity. Cell Rep. 3;2I(I):97-Io9.
Striano P, Belcastro V. (2017) Update on pharmacotherapy of myoclonic seizures. Expert Opin Pharmacother. 2017 Feb;I8(2):I87-I93. I0.1080/I4656566.2017.I280459. 23. PMID: 28067060 .

Van Egmond ME, Verschuuren-Bemelmans CC, Nibbeling EA, et al. (20I4) Ramsay hunt syndrome: Clinical characterization of progressive myoclonus ataxia caused by GOSR2 mutation. Mov Disord. 29(I):I39-43.

Van Egmond ME, Weijenberg A, Van Rijn ME, et al. (2017) The efficacy of the modified Atkins diet in North Sea Progressive Myoclonus Epilepsy: An observational prospective open-label study. Orphanet J Rare Dis. I2(I).

Van der Veen S, Zutt R, Elting JWJ, et al. (2018) Progressive myoclonus ataxia: Time for a new definition? Mov Disord. 33(8):I28I-6.

Weiss S, Melom JE, Ormerod KG, et al.(20I9) Glial $\mathrm{Ca}+$ signaling links endocytosis to $\mathrm{K}+$ buffering around neuronal somas to regulate excitability. Elife. 2019 Apr I;8. 